\title{
OSTEOCHONDRITIS DISSECANS PATELLAE
}

\author{
D. H. Edwards, Stoke-on-Trent, and G. Bentley, Liverpool, England
}

From The Nuffield Department of Orthopaedic Surgery, The Nuffield Orthopaedic Centre, Oxford

Six cases of osteochondritis dissecans patellae have been studied in five patients in an attempt to clarify the aetiology and prognosis. Assessment of the results of treatment was performed using a standard protocol. The thirty-four previous case reports in the literature are reviewed. In four of the five patients symptoms began after flexing the knee under load and three showed patellar subluxation on tangential radiographs. Thus, repetitive shearing stress on the patellar surface is thought to be an important aetiological factor. The indication for operation is a loose osteochondral fragment either wholly or partly detached from the articular surface of the patella. Vertical excision of the affected area of articular cartilage with drilling of the underlying bone gave two "good" and two "excellent" results. Healing of the drilled area and maintenance of the cartilage space was seen in radiographs of all four cases so treated. This simple method of treatment, which probably causes filling of the defect in the surface by fibrocartilage, is recommended.

Osteochondritis in the knee was first described in 1870 by Sir James Paget. This condition affects the patella alone rarely, the first case being reported by Rombold in 1936. Since then thirty-three cases have been mentioned in the literature (Hutchison 1943; Kleinberg 1949; Hay 1950; Roberts and Hughes 1950; Green and Banks 1953; DePalma 1954; Nagura 1960; Smillie 1960; Heywood 1961; Rideout, Davis and Navani 1966; Mageira 1970; Aichroth 1971; Pantazopoulos and Exarchou 1971).

Five patients with osteochondritis dissecans of the patella, one bilateral, have been seen at the Nuffield Orthopaedic Centre in the past twenty-five years. These six cases are described and previous cases are reviewed in an attempt to clarify the aetiology and prognosis.
The results in the five cases operated upon were graded on a combined assessment of symptoms and physical signs (Bentley 1970).

\section{CASE REPORTS}

Relevant clinical details of the five patients are summarised in Table $\mathrm{I}$.

Case 1-A boy aged thirteen fell from a horse and twisted his left knee. The pain settled without treatment in a few days. A year later he attended hospital with complaint of "locking" of the joint. Examination revealed a small effusion but a full range of movement. A click was felt beneath the patella at 50 degrees of flexion. The lateral radiograph showed a cavity in the lower half of the articular surface of the patella with an attached osteochondral fragment (Fig. 1). The knee was explored through a medial parapatellar incision. At operation,

TABLE I

Osteochondritis Dissecans Patellae

Clinical details of five cases

\begin{tabular}{|c|c|c|c|c|c|c|c|c|c|c|}
\hline $\begin{array}{c}\text { Case } \\
\text { number }\end{array}$ & Sex & Side & $\begin{array}{c}\text { Age at } \\
\text { onset } \\
\text { (years) }\end{array}$ & $\begin{array}{c}\text { Age at } \\
\text { operation } \\
\text { (years) }\end{array}$ & Site of lesion & Operation & $\begin{array}{c}\text { Follow-up } \\
\text { period } \\
\text { (years) }\end{array}$ & $\begin{array}{l}\text { Patellar } \\
\text { subluxation }\end{array}$ & $\begin{array}{l}\text { Radiological } \\
\text { signs of } \\
\text { healing }\end{array}$ & Result \\
\hline 1 & Male & Left & 13 & 14 & Lower medial & $\begin{array}{c}\text { Fragment excision } \\
\text { and drilling }\end{array}$ & 0.5 & No radiographs & Yes & Good \\
\hline 2 & Female & Left & 17 & 17 & Lower medial & $\begin{array}{c}\text { Fragment excision } \\
\text { and drilling }\end{array}$ & $1 \cdot 3$ & Yes & Yes & Excellent \\
\hline 3 & Male & Left & 17 & 17 & Lower lateral & $\begin{array}{c}\text { Fragment excision } \\
\text { and drilling }\end{array}$ & 3 & No radiographs & Yes & Good \\
\hline 4 & Male & Bilateral & 14 & 15 & $\begin{array}{l}\text { L. Centre- } \\
\text { medial } \\
\text { R. Centre- } \\
\text { ? medial }\end{array}$ & $\begin{array}{c}\text { Patellectomy } \\
\text { Nil }\end{array}$ & $\begin{array}{l}4 \\
4\end{array}$ & $\begin{array}{c}\text { No radiographs } \\
\text { Yes }\end{array}$ & $\begin{array}{c}\text { No } \\
\text { (patellectomy) } \\
\text { Yes }\end{array}$ & $\begin{array}{l}\text { Excellent } \\
\text { Excellent }\end{array}$ \\
\hline 5 & Female & Right & 16 & 27 & Lower lateral & $\begin{array}{l}\text { Fragment excision } \\
\text { and drilling }\end{array}$ & 15 & Yes & Yes & Excellent \\
\hline
\end{tabular}

D. H. Edwards, F.R.C.S., 177 Barlaston Old Road, Trentham, Stoke-on-Trent, Staffordshire ST4 8HJ, England.

Professor George Bentley, Ch.M., F.R.C.S., The Department of Orthopaedic Surgery, University of Liverpool, P.O. Box 147, Liverpool L69 3BX, England. 


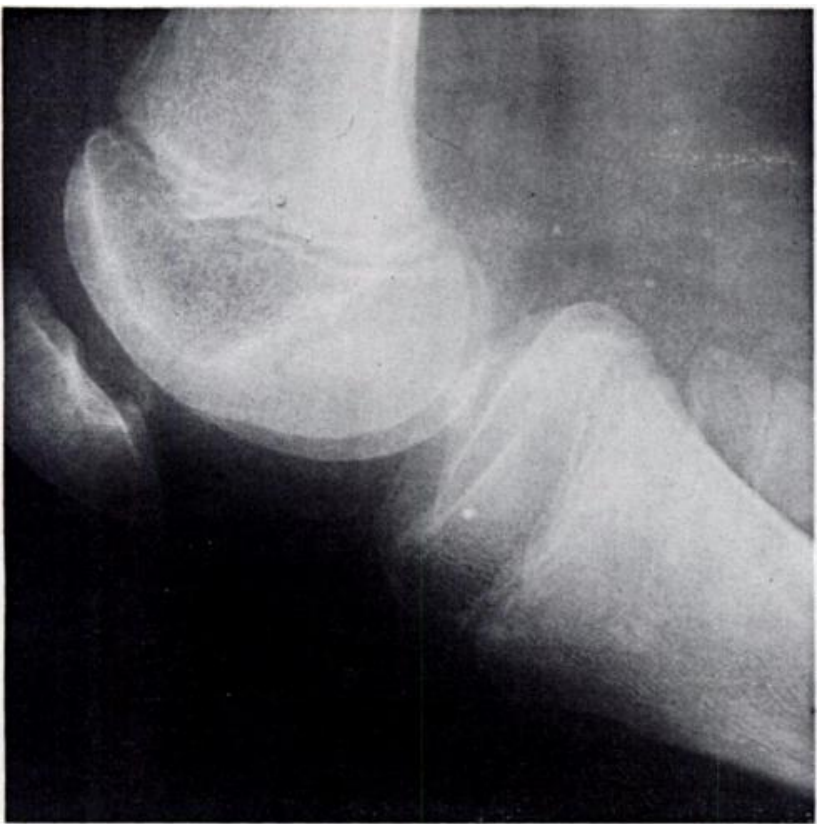

Fig. 1

Case 1-Lateral radiograph showing the defect in the posterior surface of the left patella with a partially-attached osteochondral fragment.

a defect approximately one centimetre in diameter was found in the inferior half of the medial facet of the patella, with a loose osteochondral fragment partly attached at its edge by cartilage. The fragment was excised, the cartilage at the margins of the defect were cut perpendicular to the articular surface, and the base of the defect was curetted and several fine drill holes made. The knee was enclosed in a Robert Jones bandage for two weeks after operation, and thereafter progressively mobilised.

Progress-When reviewed six months after operation, the patient still complained of clicking, with some difficulty in straightening the knee fully, but his activities, including football, were not restricted. The only abnormal sign was slight palpable retropatellar crepitus; there was no tenderness when pressure was applied over the patella. He could lift 8 kilograms with the affected knee extended, compared with 10 kilograms on the normal limb. The lateral radiograph showed partial filling of the bony defect in the patella (Fig. 2). The result was graded as "good".

Case 2-A girl aged seventeen presented with a nine weeks history of pain in the left knee felt anteriorly after squatting with the knee in flexion during gymnastics. After this episode she had developed swelling in the knee which lasted for several days. At the time of admission she complained only of pain behind the patella after activity. Examination showed a small effusion and slight tenderness over the medial joint line. A "tunnel" radiograph showed a loose body in the lateral compartment of the knee (Fig. 3), and a lateral radiograph showed a defect in the lower half of the articular surface of the patella (Fig. 4). At operation the loose body was removed from the suprapatellar pouch. The site of injury was the inferior half of the medial articular facet of the patella. Fibrous tissue was excised from an area 1.5 centimetres in diameter and the subchondral bone was drilled with a fine drill. After operation the leg was encased in a plaster of Paris cylinder for four weeks.

Progress-On review sixteen months after operation, the patient showed no restriction of activities and had no pain. The joint was normal on clinical examination, with no

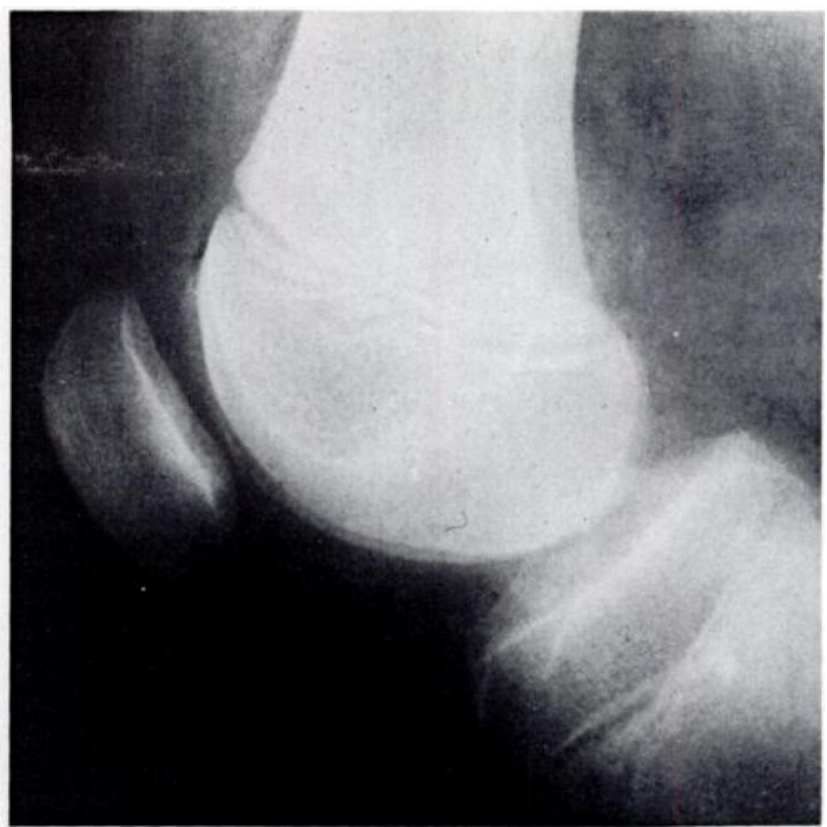

Fig. 2

Case 1-Lateral radiograph six months after excision of the osteochondritic fragment and drilling of the subchondral bone, showing partial filling of the bony defect.

tenderness or patello-femoral crepitus and a full range of movement. The quadriceps muscle was slightly wasted, but she could lift twelve kilograms with the knee straight, which was equal to the opposite normal side. The lateral radiograph showed apparent filling of the patellar defect with no sign of narrowing of the cartilage space (Fig. 5). The 60 degrees flexion patellar view showed the ghost of the previous defect and some lateral tilt of the patella suggestive of patellar subluxation (Fig. 6). The result was "excellent".

Case 3-A boy aged seventeen presented with pain in the left knee which had begun following a game of rugby football three months previously. He remembered no specific injury. The knee had become swollen and painful on weight-bearing. Two days later he found a moveable lump on the inner aspect of the knee which had reappeared on many occasions with locking. On examination he had a small effusion in the knee joint, with tenderness beneath the medial margin of the patella. A painful click was felt from the patello-femoral joint on active extension from 20 degrees of flexion.

On the lateral radiograph a partly separated osteochondritic fragment was seen attached near the lower pole of the patella.

At operation, an osteochondral loose body was removed from the suprapatellar pouch. Also a loose piece of cartilage 1.5 centimetres in diameter was excised from the medial border of the patellar defect and the underlying sclerotic bone was drilled many times with a fine drill.

Progress-At review three years after operation he was aware of "grating" in the joint but was otherwise symptomfree. He was able to play squash and tennis. Moderate patello-femoral crepitus was felt on flexing the joint, but no other abnormality was found on clinical examination. Radiographs showed filling of the bony defect in the lower pole of the patella on the lateral view, and no loss of articular cartilage space. The result was "excellent".

Case 4-An obese schoolboy first complained of catching and giving way of the left knee at the age of fourteen years. He could recall no specific injury. When seen one year after the onset of symptoms there was no effusion but slight wasting of 
the quadriceps. Firm pressure of the patella against the femur was painful; minimal crepitus in the patello-femoral articulation was detected. However, radiographs showed a large central defect in the patella (Fig. 7) with a loose body

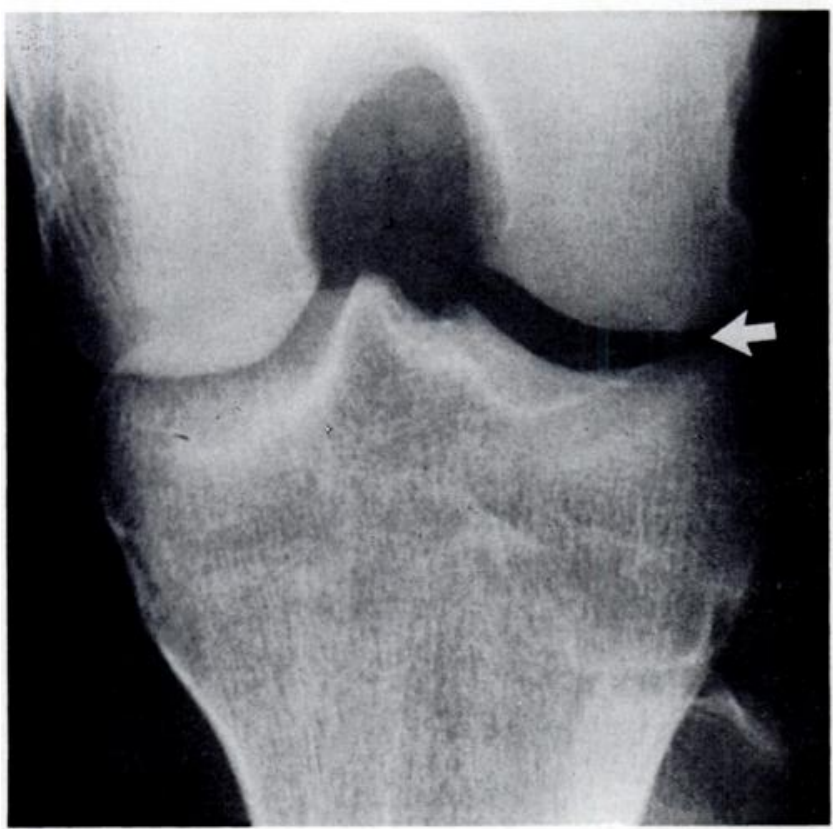

Fig. 3

Case 2-"Tunnel" radiograph of the left knee showing a small radioopaque loose body in the lateral joint compartment.

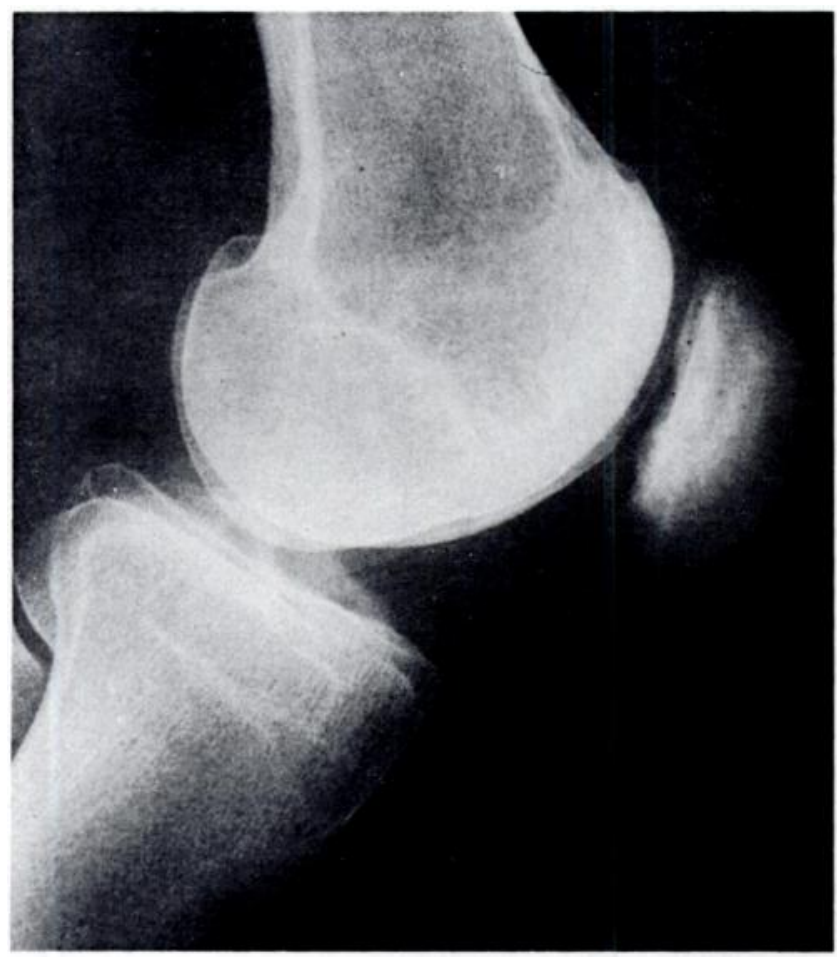

Fig. 5

Case 2-Lateral radiograph of the left knee sixteen months after excision of osteochondritic defect and drilling. Reconstitution of the bony defect is seen.

in the posterior compartment of the joint. A similar, though smaller, defect in the centre of the patella was apparent in radiographs of the right knee, but no loose body had formed.

At operation on the left knee, a deep defect measuring
8 by 12 millimetres was found in the centre of the medial facet of the patella, with a partly attached osteochondral fragment. No loose bodies were found in the joint. The patella was excised.



Fig. 4

Case 2-Lateral radiograph of the left knee. The defect in the posterior surface of the patella is obvious.

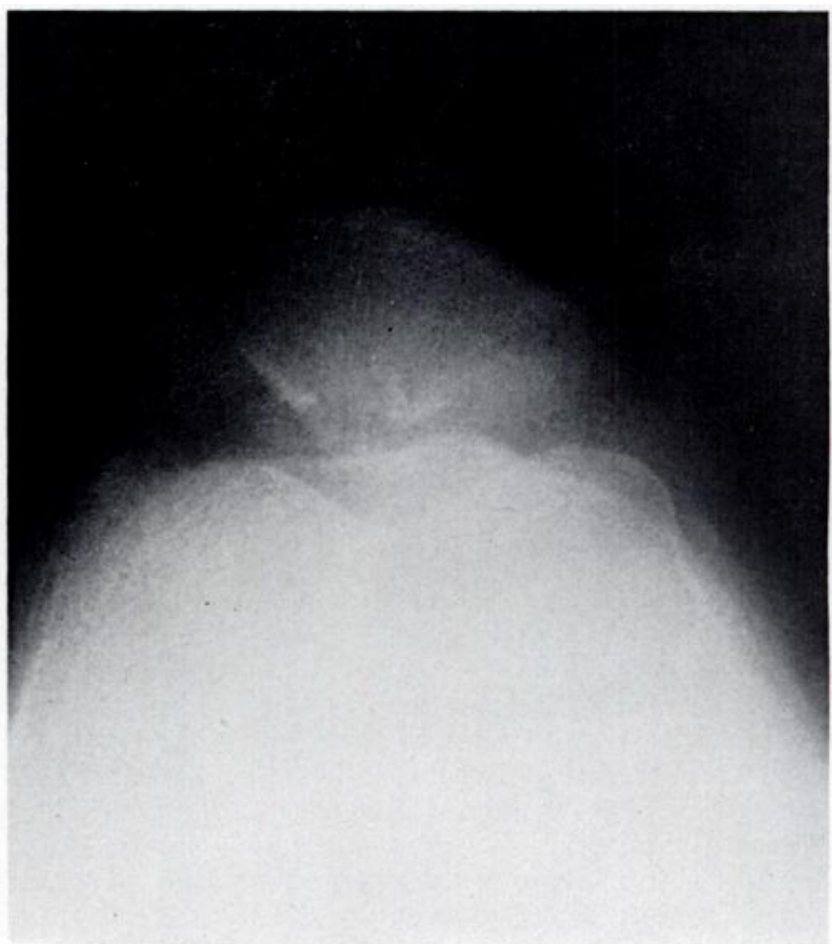

Fig. 6

Case 2-Radiograph of the left patello-femoral joint at 60 degrees of knee flexion. The lateral tilting of the patella is seen, suggesting subluxation, and also the "ghost" of the bony defect.

On histological examination reparative bone and fibrocartilage were seen in the base of the articular cartilage defect replacing the subchondral bone plate, which appeared to be totally absorbed (Fig. 8). The fibrocartilage was 


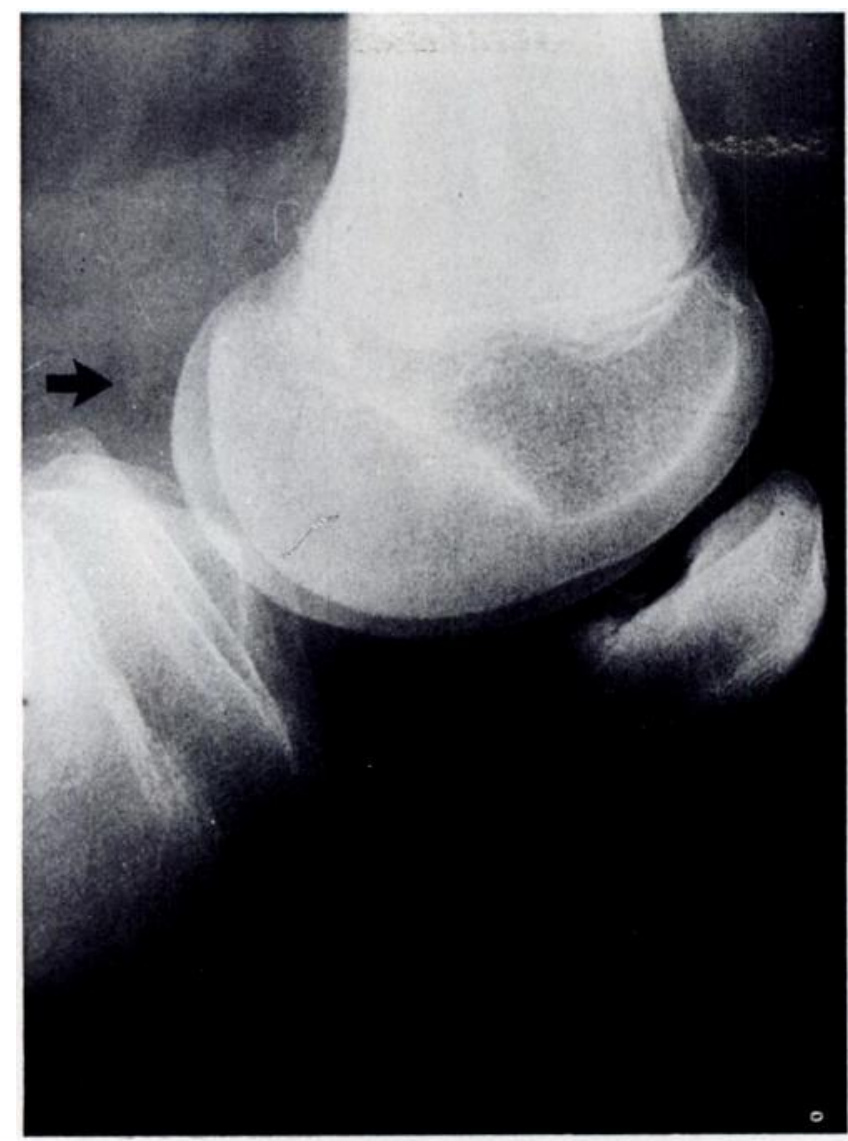

Fig. 7

Case 4 -Lateral radiograph of the left knee showing a large defect in the posterior surface of the patella and a loose body in the posterior compartment.

arising from a normal marrow which showed no evidence of avascular necrosis. The appearances were consistent with an old separation of articular cartilage and subchondral bone plate with secondary bony and fibrocartilaginous repair.

Progress-When reviewed four years later he was working as a mechanic, which involved much kneeling. He weighed 114 kilograms. He had occasional cramp-like feelings in the knee but no other symptoms. He could lift 15.9 kilograms with the knees extended on both sides. There was four centimetres wasting of the left thigh compared with the right at a point ten centimetres above the medial joint line. Radiographs showed both lateral tibial condyles to be "squared off". There were three small areas of ossification in the left patellar tendon, but no irregularity of the femoral condyle. The right, non-operated, patella showed slight irregularity of its articular surface on lateral and skyline views, but apparent healing of the defect. However the patella was obviously subluxed on the "skyline" radiograph (Fig. 9). Both knees were graded as "excellent".

Case 5-A woman first presented at the age of twenty-seven years with a history of sudden pain in the right knee on getting out of bed four years previously. The knee had "locked" just short of full extension and straightened gradually over three days. On closer questioning she admitted to intermittent locking of the knee since the age of eleven years, but denied specific injury. One month before admission she had experienced a sudden pain in the knee and was unable to flex the joint. On admission there was no effusion or localised tenderness but there was a fixed flexion deformity of

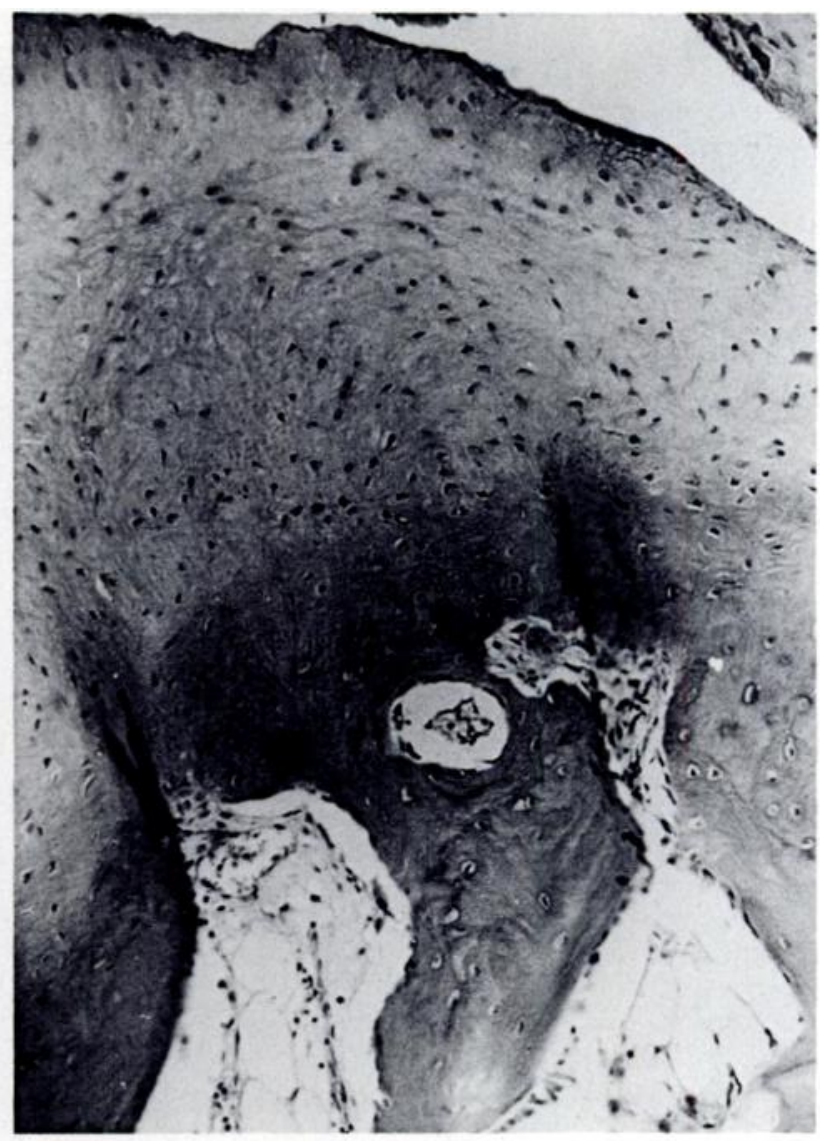

FIG. 8

Case 4-Photomicrograph of the articular surface of the excised patella taken from the area of osteochondritis dissecans. The surface is covered with repair fibrocartilage and there is a normal marrow in the underlying bone. Note the cellularity of the surface fibrocartilage and the absence of a "tidemark" between the cartilage and subchondral bone, showing that the bone and cartilage seen is of a repair type.

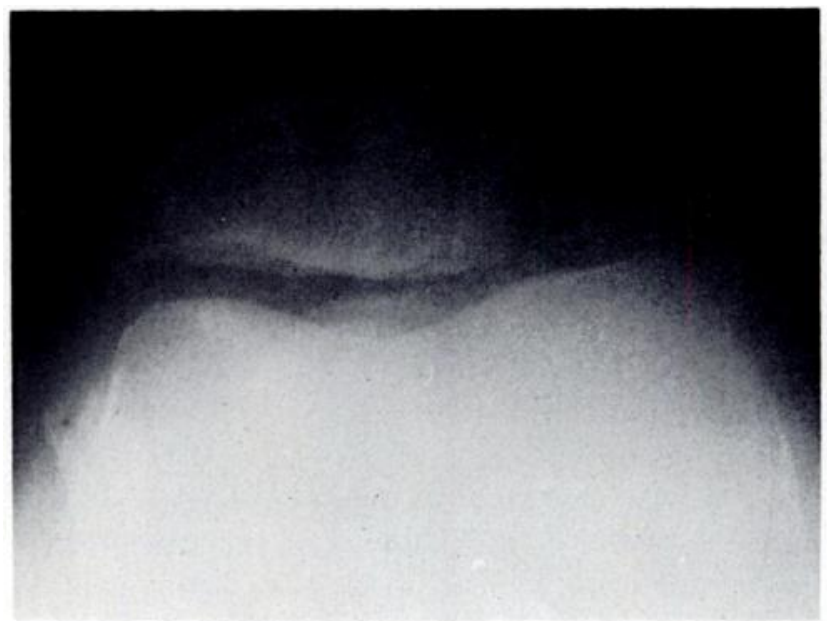

Fig. 9

Case 4-"Skyline" radiograph of the right knee demonstrating obvious lateral subluxation of the patella.

20 degrees. The lateral radiograph showed a cavity in the patella, and a loose body in the suprapatellar pouch. At operation, this loose body, 0.5 centimetre in diameter, was removed from the medial joint compartment. On the lateral facet of the articular surface of the patella there was a cavity 


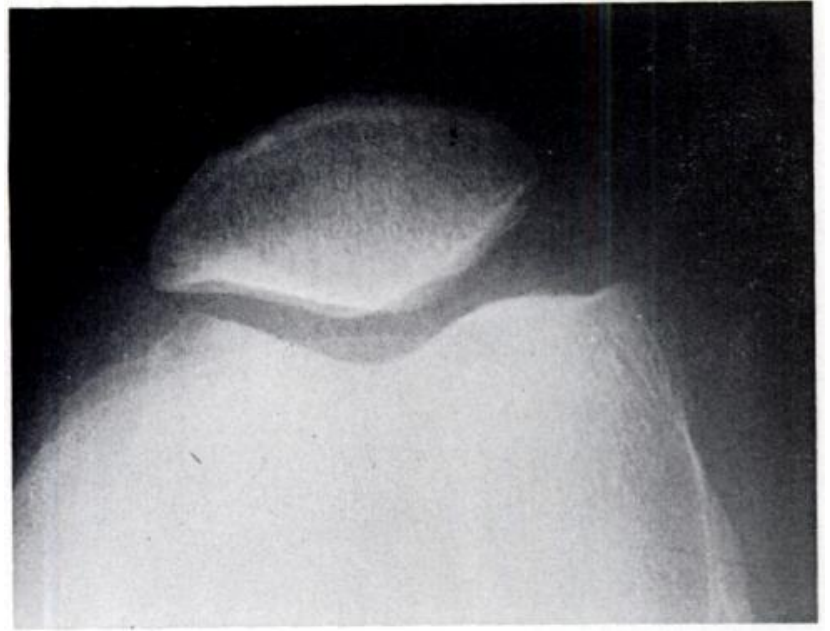

Fig. 10

Case 5-Radiograph of the right patello-femoral joint in 60 degrees of flexion. Lateral subluxation of the patella is obvious.

1 centimetre in diameter containing irregular fibrous tissue. The cavity was excised to expose subchondral bone in which many holes were made with a 1 millimetre drill.

Progress-On review fifteen years after operation, she had no complaints and no restriction of activities. The knee had a normal range of movement, with no crepitus or retro-patellar tenderness. She could lift 11.8 kilograms with the extended right knee, compared to 10 kilograms with the normal left knee. Lateral radiograph showed slight irregularity of the posterior surface of the patella, but the bony defect appeared to have filled in. It was of interest that the radiograph of the patello-femoral joint taken in 60 degrees of flexion showed obvious lateral subluxation of the patella (Fig. 10). The result was graded "excellent".

\section{DISCUSSION}

Osteochondritis dissecans of the patella has been described previously in thirty-four patients. In seven patients both patellae were involved, including one case in the present series. Full clinical details are not recorded in every case. In twenty-four patients the sex is known, there being nineteen males and five females. The age at onset of symptoms in sixteen cases was between fifteen and twenty years, as was the age at operation. With the present series forty cases have been recorded.

\section{Aetiology}

Ischaemic necrosis-The site of the osteochondritic lesion on the patella was noted in twenty-four patients. In fifteen the central area of the medial and lateral facets and in nine the lower half of the patella was involved (Fig. 11). The lateral facet of the patella (seven cases) was involved less commonly than the medial (seventeen cases), and the most medial or "odd" facet was universally spared. The sparing of the upper half is interesting also and may cast light on the aetiology.

Smillie (1960) differentiated the condition from tangential osteochondral fractures of the patella which he thought occurred on the medial facet and involved the margin of the articulating surface, whereas osteochondritis involves the non-marginal areas of bone and cartilage. Smillie (1974) also indicated that osteochondritic fragments have no blood supply, whereas osteochondral fractures do. According to Scapinelli (1967), the blood supply of the patella enters its lower pole and proceeds upwards. If the pathology of osteochondritis dissecans were related to defects of blood supply, one would expect there to be more lesions in the upper than the lower part of the bone, whereas the reverse is true.

Trauma-An alternative suggestion is that injury may play a part in causing the condition. In only seven patients in the literature was an injury recorded and the exact nature was unclear in many. Depending on their severity direct blows on the patella produce stellate fractures of the articular cartilage (Hunter 1974) or bone (Watson-Jones 1955) rather than discrete osteochondral fragments. On the other hand the frequent occurrence of a single osteochondritic fragment attached by one margin suggests that a tangential shearing force is responsible for the lesion.

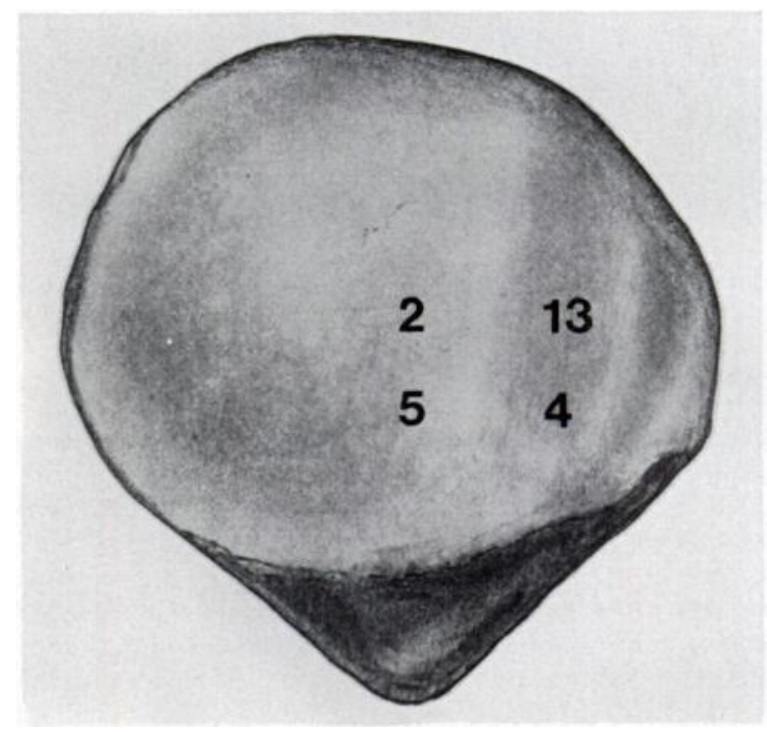

Fig. 11

Diagram of the undersurface of a left patella to show the distribution of reported cases of osteochondritis dissecans patellae. Note the predominance of medial facet lesions and the complete sparing of the "odd" facet and the upper half of the bone.

The history in four out of five of our patients who had pain, beginning when the knee was flexed under load, supports the concept of a shearing force on the patella as the precipitating cause. A single shearing stress would probably not produce death of subchondral bone described in osteochondritic fragments, but repeated shearing stresses, associated with recurrent subluxation of the patella, could cause gradual loosening of the fragment and thus ischaemic necrosis. Three of our cases showed definite lateral patellar subluxation, which supports this explanation. Appropriate radiographs were not taken of the other three knees. Recurrent 
subluxation is difficult to diagnose, clinically and radiologically, and requires tangential radiographs of the patella taken in 30 and 60 degrees of flexion of the knee with the quadriceps relaxed (Ficat 1973).

\section{Treatment}

Five of the six knees operated on had a loose body, either totally or partly detached, as the cause of symptoms whereas the knee treated conservatively had no loose body and was free from symptoms and remained so. Thus the main indication for operation is the presence of a loose body. Vertical excision of the defect in the patellar articular cartilage and drilling of subchondral bone is a rational method of treatment. Such defects made in the articular surface of animal joints usually heal, especially in the immature, by metaplasia of the tissue within the defect to fibrocartilage or even hyaline cartilage (DePalma, McKeever and Subin 1966). This method was satisfactory in the four knees so treated. Symptoms at review were minimal and the patellofemoral joint space showed no narrowing on lateral radiographs, suggesting preservation of the articular cartilage. Moreover, the bony defect appeared healed in the four knees treated by excision of the defect and drilling of the subchondral bone. It appears that attempts to reattach fragments would be unwise in a highlyloaded articulation such as the patello-femoral joint. Patellectomy appears to be too radical a procedure except where a very large defect of more than 2 centimetres diameter is present; this is unlikely to heal due to lack of support by the surrounding intact articular cartilage.

We are grateful to the consultant staff of the Nuffield Orthopaedic Centre, Oxford, for permission to study their patients. The manuscript was typed by Mrs J. M. Lever and the illustrations prepared by Mr R. Emmanuel.

\section{REFERENCES}

Aichroth, P. (1971) Osteochondritis dissecans of the knee. Journal of Bone and Joint Surgery, 53-B, 440-447.

Bentley, G. (1970) Chondromalacia patellae. Journal of Bone and Joint Surgery, 52-A, 221-232.

DePalma, A. F. (1954) Diseases of the Knee. Philadelphia, London, Montreal: J. B. Lippincott Company.

DePalma, A. F., McKeever, C. D., and Subin, D. K. (1966) Process of repair of articular cartilage demonstrated by histology and autoradiography with tritiated thymidine. Clinical Orthopaedics and Related Research, 48, 229-242.

Ficat, P. (1973) Les Déséquilibres Routuliens. Paris: Masson et Cie.

Green, W. T., and Banks, H. H. (1953) Osteochondritis dissecans in children. Journal of Bone and Joint Surgery, 35-A, 26-47.

Hay, B. M. (1950) Two cases of osteochondritis dissecans affecting several joints. Journal of Bone and Joint Surgery, 32-B, 361-367.

Heywood, A. W. B. (1961) Recurrent dislocation of the patella. Journal of Bone and Joint Surgery, 43-B, 508-517.

Hutchison, R. G. (1943) Osteochondritis dissecans. British Journal of Radiology, N.S. 16, 147-149.

Kleinberg, S. (1949) Bilateral osteochondritis dissecans of the patella. Journal of Bone and Joint Surgery, 31-A, 185-186.

Mageira, J. (1970) Kasuistischer Beitrag zur Osteochondrosis dissecans der Patella beider Kniegelenke. Beitrage zur Orthopädie und Traumatologie, 17, 314-336.

Nagura, S. (1960) The so-called osteochondritis dissecans of König. Clinical Orthopaedics, 18, 100-122.

Paget, J. (1870) On the production of some of the loose bodies in joints. Saint Bartholomew's Hospital Reports, 6, 1-4.

Pantazopoulos, T., and Exarchou, E. (1971) Osteochondritis dissecans of the patella. Journal of Bone and Joint Surgery, 53-A, 1205-1207.

Rideout, D. G., Davis, S., and Navani, S. V. (1966) Osteochondritis dissecans patellae. British Journal of Radiology, N.S. 39, 673-675.

Roberts, N., and Hughes, R. (1950) Osteochondritis dissecans of the elbow joint. Journal of Bone and Joint Surgery, 32-B, 348-360.

Rombold, C. (1936) Osteochondritis dissecans of the patella. Journal of Bone and Joint Surgery, 18, 230-231.

Scapinelli, R. (1967) Blood supply of the human patella. Journal of Bone and Joint Surgery, 49-B, 563-570.

Smillie, I. S. (1960) Osteochondritis Dissecans. Edinburgh and London: E. \& S. Livingstone Ltd.

Smillie, I. S. (1974) Diseases of the Knee Joint. Edinburgh and London: Churchill Livingstone.

Watson-Jones, Sir R. (1955) Fractures and Joint Injuries. Fourth edition. Vol. II, pp. 788-789. Edinburgh and London: E. \& S. Livingstone Ltd. 